\title{
IMPACT OF QUALITY INDICATORS ON THE PERFORMANCE OF CLINICAL SEROLOGY LABORATORY
}

\author{
D. Sudha Madhuri ${ }^{1}$, A. Swathi², K. Nagamani ${ }^{3}$
}

${ }^{1}$ Assistant Professor, Department of Microbiology, Gandhi Medical College, Secunderabad.

${ }^{2}$ Assistant Professor, Department of Microbiology, Kamineni Academy of Medical Sciences and Research Centre, LB Nagar, Hyderabad. 3 Professor and HOD, Department of Microbiology, Gandhi Medical College, Secunderabad.

\begin{tabular}{l}
\hline ABSTRACT \\
BACKGROUND \\
Monitoring of quality indicators covering the critical areas of total testing process in pre-analytical, analytical and post-analytical \\
phases have a significant impact on performance of laboratory as $80-90 \%$ of clinical diagnosis and treatment is made on the basis \\
of laboratory test results in healthcare.
\end{tabular}

Aim of the study is to evaluate the performance of serology laboratory with the implementation of set of quality indicators.

Study Design - This is a prospective observational study conducted in serology section of clinical microbiology laboratory, Gandhi Hospital, Hyderabad, from July 2013 to June 2014.

\section{MATERIALS AND METHODS}

All the blood/serum samples received for routine serology were included in the study. A total of 32,026 samples were received and analysed using rapid methods and ELISA. Quality indicators selected were Sample Rejection Rate (SRR), incomplete Test Request Form (TRF), repeat testing, Proficiency Testing Performance (PTP) failures evaluation by EQAS and ILC, Turnaround Time (TAT) and Critical alert reporting. Selected indicators were monitored progressively over time.

\section{RESULT}

A significant change in performance of serology laboratory observed after implementation of Quality indicators. Major impact was observed in incomplete TRF, which reduced from $16.34 \%$ to $4.5 \%$ followed by reduced sample rejection rate from $9.82 \%$ to $1.50 \%$. Most significant improvement was observed in pre-analytical phase and post-analytical phase, but not much impact on analytical phase in Total Testing Process (TTP).

\section{CONCLUSION}

Quality indicators have huge impact on the performance of diagnostic laboratory services in patient care.

\section{KEYWORDS}

Test Request Form (TRF), Quality Indicator (QI), TAT (Turn Around Time).

HOW TO CITE THIS ARTICLE: Madhuri DS, Swathi A, Nagamani K. Impact of quality indicators on the performance of clinical serology laboratory. J. Evolution Med. Dent. Sci. 2016;5(85):6300-6303, DOI: 10.14260/jemds/2016/1423

\section{BACKGROUND}

Laboratory services play a key role in health outcomes. Quality indicators have been advocated for use as internal quality assessment tools to evaluate all phases of total testing process to identify, correct and monitor the errors in improvement of the performance of laboratory services. Quality assurance plays a major role in the patient care, as $80 \%$ of clinical diagnosis and treatment is based on laboratory reports. ${ }^{1}$ No other field of medicine is better positioned than laboratory medicine in control and prevention of disease and disease surveillance by providing timely information. ${ }^{2}$ Quality indicators are measured information qualitative or quantitative which indicates the performance of a process, determines quality of services, identifies areas that Financial or Other, Competing Interest: None.

Submission 19-06-2016, Peer Review 12-10-2016,

Acceptance 19-10-2016, Published 21-10-2016.

Corresponding Author:

Dr. D. Sudha Madhuri,

Assistant Professor,

Department of Microbiology,

Gandhi Medical College,

Secunderabad.

E-mail: sudha_devara@yahoo.com

DOI: $10.14260 /$ jemds/2016/1423

\section{(c) $(1) \odot$}

need further improvement and track changes over time. (Standard UNI 11097).3 International organisation for standardisation for medical laboratories ISO-15189:2012 recommended the use of quality indicators for the assessment and continuous monitoring of QMS in the laboratory for timely, accurate results to meet patient needs. ${ }^{4,5}$

\section{Objectives of the Present Study}

1. The main objective of the study was to analyse the impact of quality indicators in the performance of the serology laboratory.

2. Quality assurance in reporting of results.

\section{MATERIALS AND METHODS}

This was a prospective observational study conducted in serology section of Clinical Microbiology Laboratory, Gandhi Hospital, Hyderabad, from July 2013 to June 2014. All the blood/serum samples received for routine serology were included in the study. Samples for routine culture were excluded from the study. A total of 32,026 samples, $70 \%$ were from outpatient clinics and 30\% from inpatient wards were received and analysed using rapid methods (Immunoblot, Agglutination) and ELISA. 
Quality indicators selected were those for which errors were frequent and improvements was possible, monitoring the critical step of total testing process and measurement of which on long-term basis was possible.

Quality indicators were selected to observe critical areas of Total Testing Process (TTP). In Pre-Analytical Phase: incomplete Test Request Form (TRF), Sample Rejection Rate (SRR), Haemolysed/Clotted Samples, Insufficient Sample, Wrong Identification; in Analytical Phase: Random errors, repeat testing, Proficiency Testing Performance (PTP) evaluation and In Post Analytical Phase: Critical alert reporting, Turnaround Time (TAT) were selected.

In pre-analytical phase upon receiving samples along with the test request form, the technician in the reception screens and documents all components of pre-analytical phase with predesigned checklist designed by the laboratory for the acceptance and rejection of the sample by unique identification number (Aadhar card number, registration number, date of birth) demographic data (Name, age, sex, address, occupation), brief relevant clinical history, list of tests requested with signature and contact number of the treating physician. The doctor in-charge verify TRF with sample, proper tubes for collection, transporting conditions, adequacy and integrity of samples (Haemolysed/clotted/lipemic) for the tests requested.

During analytical phase, Random errors, Repeat testing, Proficiency Testing Performance (PTP), evaluation by EQAS and ILC were monitored.

In post-analytical phase critical alerts and (TATs) as performance indicators monitored.

Lab Personnel Awareness and Accidents Reported were monitored in all phases of the TTP. Accidents reported in the lab included in the study were needle stick injury, gloves not worn during handling the samples, spillage of samples in working area and waste disposal in wrong bag.

As part of Continuous Medical Education (CME), the laboratory technical staff, medical and nursing staff of the clinical departments were periodically trained and sensitised to quality system procedures including filling of TRF, sample collection techniques, documentation, maintenance of records, SOP writing and reporting of critical results by group discussions and practical demonstrations in our laboratory and in OPDs and in wards and observable change was noticed in the laboratory by clinical staff.

In the present study of impact of quality indicators in monitoring QMS is compared to Phase-I, which extended from July-2012 to June-2013 in which no proper monitoring of QI observed. Improvement noticed for all the selected QIs after implementation and monitoring of Quality indicators.

\section{RESULTS}

Table 1 - Shows the list of Quality indicators selected and monitored during pre-analytical, analytical and postanalytical phase of Total Testing Process.

Table 2 - Shows monitoring of Quality Indicators during study period from July 2013 to June 2014. During preanalytical phase, poorly controlled quality indicator was incomplete TRF (4.5\%), which was followed by sample rejection rate $(1.5 \%)$. The most common cause of sample rejection was inadequate quantity of sample received $(2.75 \%)$ followed by haemolysis $(0.74 \%)$ and wrong identification $(0.05 \%)$.

In analytical phase, random errors, repeat testing and non-conformity to proficiency testing were analysed; 1400 $(4.37 \%)$ tests were retested. All the results of retesting were under predefined coefficient of variable (CV \%) of the lab. Random Errors was seen in $18(0.05 \%)$ cases and nonconformity to QC was observed $1(0.003 \%)$ time during our study.

The lab has defined the TAT of 4-6 hours for rapid tests and 72 hours for ELISA tests. In our lab, we do not have LIS system and only manual reporting was done. In $24(0.07 \%)$ instances, the test results could not be dispatched in stipulated time; $16(0.04 \%)$ critical values could not be communicated to the concerned physician.

Table 3 - Shows the assessment of lab personnel's awareness by CMEs and trainings on various aspects of the quality system procedures in the laboratory. It was observed that mean score of lab personnel's awareness is improved from 4.2 to 8.9 after sensitisation.

Table 4 - Shows the effect of intervention and implementation of Quality Indicators (QIs) in different phases of Total Testing Process (TTP) in comparison to the preintervention period.

\begin{tabular}{|c|c|c|c|}
\hline Pre-Analytical & Analytical & Post-Analytical & All Phases \\
\hline Incomplete Test Request Form (TRF) & Random Error & Critical Value Reporting & No. of Accidents Reported \\
\hline Sample Rejection Rate (SRR) & Repeat testing & Turn Around Time (TAT) & Lab Personnel Awareness \\
\hline Haemolysed/Clotted Samples & Non-Conformity to PT & & \\
\hline Insufficient Sample & & & \\
\hline Wrong Identification & & & \\
\hline
\end{tabular}

\begin{tabular}{|c|c|c|c|}
\hline $\begin{array}{c}\text { Pre-Analytical Phase } \\
\text { Indicators Tested and Percentage (\%) }\end{array}$ & $\begin{array}{c}\text { Analytical Phase Indicators } \\
\text { Tested and } \\
\text { Percentage (\%) }\end{array}$ & $\begin{array}{c}\text { Post-Analytical Phase } \\
\text { Indicators Tested and } \\
\text { Percentage (\%) }\end{array}$ & $\begin{array}{c}\text { All Phases Indicators } \\
\text { Tested and Percentage } \\
(\%)\end{array}$ \\
\hline $\begin{array}{c}\text { Incomplete Test Request Form (TRF) } \\
1442(4.50 \%)\end{array}$ & $\begin{array}{c}\text { Number of Repeat Testing } \\
1400(4.37 \%)\end{array}$ & $\begin{array}{c}\text { Critical Value Reporting 16 } \\
(0.04 \%)\end{array}$ & $\begin{array}{c}\text { Lab Personnel Awareness } \\
\text { gain from } 4.25 \text { to } 8.9 \%\end{array}$ \\
\hline $\begin{array}{c}\text { Sample Rejection Rate (SRR) } \\
481(1.50 \%)\end{array}$ & $\begin{array}{c}\text { Random Errors } \\
18(0.05 \%)\end{array}$ & $\begin{array}{c}\text { Turn Around Time (TAT) } \\
24(0.07 \%)\end{array}$ & $\begin{array}{c}\text { No. of Accidents Reported - } \\
\text { NIL }\end{array}$ \\
\hline Haemolysed/Clotted Sample $87(0.27 \%)$ & $\begin{array}{c}\text { Outliers In Proficiency } \\
\text { Testing 1 (0.003\%) }\end{array}$ & & \\
\hline Insufficient Sample 384 (1.19\%) & & & \\
\hline Wrong Identification 10 (0.03\%) & \multicolumn{2}{|c|}{} \\
\hline \multicolumn{2}{|r|}{ Table 2. Percentage of Each Quality Indicators Monitored in Different Phases of } \\
Total Testing Process during 1 Year: July 2013 - June 2014, (n = 32,026)
\end{tabular}




\begin{tabular}{|c|c|c|c|}
\hline Phase of Observation & Maximum Marks & $\begin{array}{c}\text { Total Score by Lab } \\
\text { Personnel }\end{array}$ & Average Score (n=10) \\
\hline Before sensitization & 100 & 42 & $4.2 \%$ \\
\hline After sensitization & 100 & 89 & $8.9 \%$ \\
\hline \multicolumn{2}{|c|}{ Table 3. Lab Personnel Awareness } \\
\hline
\end{tabular}

\begin{tabular}{|c|c|c|c|c|}
\hline Parameter & $\begin{array}{c}\text { Pre-Intervention Period } \\
\text { July } 2012 \text { - June } 2013 \text { (Before Initiating the Study } \\
\text { Percentage (\%) } \\
\text { n=11955 }\end{array}$ & $\begin{array}{c}\text { Intervention period } \\
\text { July } 2013-\text { June } \\
2014 \\
\text { Percentage }(\%) \\
\text { n=32026 }\end{array}$ & McNemar & $\begin{array}{c}\text { P- } \\
\text { value }\end{array}$ \\
\hline \multicolumn{5}{|c|}{ Pre-Analytical Phase } \\
\hline Incomplete Forms & $1954(16.34 \%)$ & $1442(4.50 \%)$ & 71.08 & $<0.05$ \\
\hline Sample Rejection Rate (SRR) & $1174(9.82 \%)$ & $481(1.50 \%)$ & 85.78 & $<0.05$ \\
\hline Haemolysed/Clotted Sample & $135(1.12 \%)$ & $87(0.27 \%)$ & 98.07 & $<0.05$ \\
\hline Insufficient Sample & $425(3.6 \%)$ & $384(1.19 \%)$ & 92.88 & $<0.05$ \\
\hline Wrong Identification & $614(5.13 \%)$ & $10(0.03 \%)$ & 94.78 & $<0.05$ \\
\hline \multicolumn{5}{|c|}{ Analytical Phase } \\
\hline Number of Repeat Testing & $1256(10.50 \%)$ & $1400(4.37 \%)$ & 77.20 & $<0.05$ \\
\hline Random Errors & $32(0.26 \%)$ & $18(0.05 \%)$ & 99.59 & $<0.05$ \\
\hline $\begin{array}{c}\text { Outliers In Proficiency } \\
\text { Testing. }\end{array}$ & $2(0.01 \%)$ & $1(0.003 \%)$ & 99.98 & $<0.05$ \\
\hline \multicolumn{5}{|c|}{ Post-Analytical Phase } \\
\hline Critical Value Reporting & $30(0.25 \%)$ & $16(0.04 \%)$ & 99.63 & $<0.05$ \\
\hline $\begin{array}{l}\text { Turnaround Time (TAT) not } \\
\text { met }\end{array}$ & $132(1.10 \%)$ & $24(0.07 \%)$ & 98.69 & $<0.05$ \\
\hline \multicolumn{5}{|c|}{ In All Phase } \\
\hline Accidents in the lab & $3(0.025 \%)$ & $0(0.00 \%)$ & 97.00 & $<0.05$ \\
\hline $\begin{array}{r}\text { Table 4. Eff } \\
T\end{array}$ & Intervention in Implementing Quality Indicato & $\begin{array}{l}\text { 5) in Different Ph } \\
\text { ention Period }\end{array}$ & $f$ & \\
\hline
\end{tabular}

\section{DISCUSSION}

Monitoring of correct performance of the Total Testing Process of the laboratory is very important, as it helps to identify errors but also to formulate quality improvement strategies to prevent an error from sample collection, transportation, analysis of sample to the reporting of test results invalidates the quality of the test results. 6,7

During the pre-analytical phase, incomplete TRF received in the lab was the poorest quality indicator observed (4.5\%), which was followed by sample rejection rate $(1.5 \%)$ close to the rate reported by Chawla et al (1.54\%). ${ }^{8}$ The most common cause of sample rejection was inadequate quantity of sample received $(2.75 \%)$ followed by haemolysis $(0.74 \%)$ and wrong identification $(0.05 \%)$. Reasons for inadequate quantity and haemolysis may be due to repeated sampling in already sick patients, which leads to collapse of veins which makes it difficult to take appropriate amount of sample. Regular training of lab technicians and clinical staff on sample collection techniques was done, which led to reduction in sample rejection due to inadequate quantity of sample from $5.13 \%$ to $1.19 \%$. Meticulous screening of prefixed checklist initiated. The staff was trained in proper labelling of samples, correct filling of TRF which has led to significant improvement in pre-analytical errors due to incomplete TRF reduced from $16.34 \%$ to $4.50 \%$. Introduction of colour coded vacutainers and central lab collection facilities to avoid repeat sampling for different tests has been done. For any add-on additional tests, samples were stored for 72 hours at $2-40 \mathrm{C}$. There was a remarkable decrease in errors in preanalytical phase.
In analytical phase, $4.37 \%$ tests were retested. Repeat tests were done on the same samples to reconfirm the results in case of doubt at laboratory level and on request by physicians. All the results were under predefined coefficient of variable (CV \%) of the lab; $18(0.05 \%)$ instances of random errors observed which may be due to Pipetting Error, Calibration Failure and Instability of reagents or Calibration drift. These errors were detected on regular monitoring of Levy Jennings (LJ) chart for each test parameter. Participation in EQAS/ILC was done. Non-conformity to PT was observed only one time $(0.20 \%)$. It may be due to inappropriate storage of reconstituted QC material in the lab. Standard Operation Procedures (SOPs) were written and implemented to regulate Random Errors in our laboratory. A checklist was developed to ensure proper storage and maintenance of reagents/kits, pipettes and instruments were checked regularly and more stringently. Sensitisation of staff for the same was done as part of intervention.

A questionnaire with multiple choice questions covering various aspects of quality system and procedures in Total Testing Process was prepared and approved by Quality Manager. Questionnaire was given to test the knowledge and awareness of the laboratory personnel before and after sensitisation and training of the laboratory staff and total gain was calculated in terms of marks. Mean score improved from 4.2-8.9. The lab personnel showed a marked improvement in knowledge, but also their readiness to implement the policies and procedures laid down in the laboratory to ensure patient safety and good laboratory practices after sensitisation. 
In the post-analytical phase, critical value reporting and TATs were monitored. Critical value reporting is defined as values that represent situations that could be life-threatening without treatment.9,10 The literature shows failure of critical value reporting $0.1 \%$ to $1.4 \%$. In our laboratory, $0.04 \%$ critical values could not be communicated to the concerned physician. Our lab has defined TAT as 24 hrs. for Rapid Tests and $72 \mathrm{hrs}$. for ELISA. In $24(0.07 \%)$ instances, the test results could not be dispatched in stipulated time as we do not have LIS system and only manual reporting is done.

\section{CONCLUSION}

Quality indicators have huge impact on the performance of diagnostic laboratory services in patient care, as every step in the Total Testing Process is prone to errors. To improve the quality of the reported results, a systematic monitoring and evaluation of laboratory performance by different quality indicators covering critical areas of Total Testing Process is extremely a valuable tool.

\section{REFERENCES}

1. Bonini P, Plebani M, Ceriotti F, et al. Errors in laboratory medicine. Clinical Chemistry 2002;48(5):691-8.

2. WHO. Strengthening public health laboratories in WHO African region: a critical need for disease control 2008.
3. UNI 11097. Quality management-quality indicators and quality management Synoptical Tables-General Guidelines 2003.

4. Shahangian S, Snyder SR. Laboratory medicine quality indicators: a review of the literature. American Journal of Clinical Pathology 2009;131(3):418-31.

5. International Organization for Standardization. ISO15189: Medical Laboratories Requirements for Quality and Competence. Geneva 2012.

6. Salinas M, Lopez-Garrigos M, Gutierrez M, et al. Two minutes of monthly monitoring can ensure quality laboratory service everyday of the year. Lab Medicine 2010;41(6):360-3.

7. Phlebani M. Exploring the iceberg of errors in laboratory medicine. Clin Chim Acta 2009;404(1):16-23.

8. Chawla R, Goswami B, Singh B, et al. Evaluating laboratory performance with quality indicators. Lab Medicine 2010;41(5):297-300.

9. Howanitz PJ, Steindel SJ, Heard NV. Laboratory critical values policies and procedures: a college of American pathologists Q-probe study in 623 institutions. Arch Pathol Lab Med 2002;126(6):663-9.

10. Dighe AS, Jones JB, Parham S, et al. Survey of critical value reporting and reduction of false-positive critical value results. Arch Pathol Lab Med 2008;132(10):166671. 